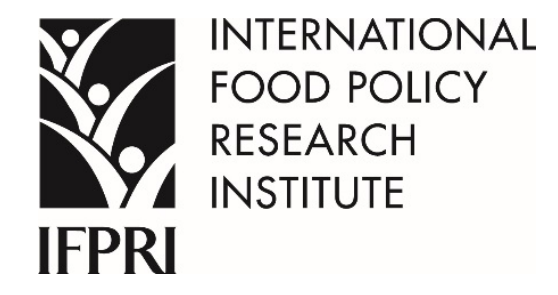

IFPRI Discussion Paper 01505

January 2016

\title{
Volatile Volatility
}

Conceptual and Measurement Issues Related to Price Trends and Volatility

\section{Eugenio Díaz-Bonilla}

Markets, Trade and Institutions Division 


\section{INTERNATIONAL FOOD POLICY RESEARCH INSTITUTE}

The International Food Policy Research Institute (IFPRI), established in 1975, provides evidence-based policy solutions to sustainably end hunger and malnutrition and reduce poverty. The Institute conducts research, communicates results, optimizes partnerships, and builds capacity to ensure sustainable food production, promote healthy food systems, improve markets and trade, transform agriculture, build resilience, and strengthen institutions and governance. Gender is considered in all of the Institute's work. IFPRI collaborates with partners around the world, including development implementers, public institutions, the private sector, and farmers' organizations, to ensure that local, national, regional, and global food policies are based on evidence. IFPRI is a member of the CGIAR Consortium.

\section{AUTHOR}

Eugenio Díaz-Bonilla (E.Diaz-Bonilla@cgiar.org) is a visiting senior research fellow in the Markets, Trade and Institutions Division of IFPRI, Washington, DC.

\section{Notices}

1. IFPRI Discussion Papers contain preliminary material and research results and are circulated in order to stimulate discussion and critical comment. They have not been subject to a formal external review via IFPRI's Publications Review Committee. Any opinions stated herein are those of the author(s) and are not necessarily representative of or endorsed by the International Food Policy Research Institute.

2. The boundaries and names shown and the designations used on the map(s) herein do not imply official endorsement or acceptance by the International Food Policy Research Institute (IFPRI) or its partners and contributors.

Copyright 2016 International Food Policy Research Institute. All rights reserved. Sections of this material may be reproduced for personal and not-for-profit use without the express written permission of but with acknowledgment to IFPRI. To reproduce the material contained herein for profit or commercial use requires express written permission. To obtain permission, contact ifpri-copyright@cgiar.org. 


\section{Contents}

Abstract $\quad$ V

Acknowledgments $\quad$ vi

1. Introduction 1

2. Price Levels and Price Volatility 2

3. Different Measures and Concepts of Trends and Volatility 5

4. Conclusions 18

$\begin{array}{ll}\text { References } & 19\end{array}$ 


\section{Tables}

3.1 Food price volatility in nominal and real terms $\quad 7$

3.2 Food price volatility in US dollars and SDRs 9

3.3 Different indicators of volatility 14

Figures

3.1 Food price indexes (in US dollars): Nominal (right axis) and real (left axis) (2005=100) 5

3.2 Trends in world GDP growth (right axis) and in food price nominal inflation (left axis) 6

3.3 Effective nominal US exchange rate (left axis) and nominal food price index (right axis) 8

3.4 Nominal food price indexes in US dollars and SDRs (2005=100 for USD) 8

3.5 Terms-of-trade index (median value; $2000=100$ ) 11

3.6 Food price index in nominal US dollars: LT trend and cycle 12

3.7 Food price index in nominal US dollars: HP trend and cycle 13

3.8 Food price index in nominal US dollars: CF trend and cycle 13

3.9 Trends, cycles, and spikes in food prices 15

3.10 Agricultural imports as percentage of total merchandise exports 17 


\begin{abstract}
In the 1990s, policy debates focused on global price levels and whether they were too low. Two recent food price spikes, in 2008 and 2011, have led to renewed concerns about the impact of high prices and shifted the focus back to food price volatility. The effects of changes in price trends on food production and food consumption (a discussion about price levels) are different from the effects of volatility changes around those trends (cycles and extreme events), but the two issues are related. This paper argues that analysis of these developments may benefit from differentiating between trends, cycles, and shorter-term events, including spikes and busts. After expanding on several methodological and data issues related to how these concepts are defined and measured, the paper concludes that although the price shocks of 2008 and 2011 focused the attention of the public and policymakers on price volatility, the decomposition of trends, cycles, and shorter-term volatility also suggests the need to find out whether price variations are responding to cyclical and shorter-term movements, or whether they are the result of a changing trend reflecting adjustments in long-term fundamentals that need to be properly understood.
\end{abstract}

Keywords: volatility, food security, macroeconomics 


\section{ACKNOWLEDGMENTS}

I thank Joachim von Braun, Maximo Torero, and Matthias Kalkuhl for their detailed comments on earlier versions of this paper. However, they are not responsible for my own errors and omissions. A version of this discussion paper will appear as a chapter in Kalkuhl, M., J. von Braun, and M. Torero, ed. 2016. Food Price Volatility and Its Implications for Food Security and Policy. New York: Springer.

The statements and opinions expressed in this paper are those of the author and should not be construed as institutional positions. 


\section{INTRODUCTION}

It is obvious that prices are crucial variables (although certainly not the only ones) in decisions pertaining to production and consumption. Producers and consumers alike are affected by both price levels and changes in price levels (variability or volatility). In the case of agricultural and food policies, debates have arisen about adequate price levels for food products and ways to reduce price volatility to such a degree that it does not interfere with the signaling effects of prices in economic decisions. These policy issues revolve around balancing the interests of producers and consumers in increasingly differentiated societies in both industrialized and developing countries.

In the 1990s, policy debates focused on global price levels and whether they were too low. Two recent price spikes, in 2008 and 2011, have led to renewed concerns about the impact of high food prices and shifted the focus back to food price volatility. The effects of changes in price trends on food production and food consumption (a discussion about price levels) are different from the effects of changes in volatility around those trends (cycles and extreme events), but the two issues are related. Policy analyses addressing these developments require clarification of some questions about both price levels and their variability (Díaz-Bonilla and Ron 2010), such as what to measure (including the appropriate time frame and currency) and how to measure (for instance, how to characterize trends given the existence of different detrending methods; see, for instance, Canova 1998, 1999). The following section briefly discusses several topics related to the impacts of price trends and variability. Then Section 3 , which represents the bulk of the discussion, analyzes various issues related to what to measure and how to do it. A final section offers conclusions. 


\section{PRICE LEVELS AND PRICE VOLATILITY}

\section{Price Levels}

Price levels affect producers' profits (and therefore their incentives to produce) and food costs to consumers (and consequently their purchasing decisions and economic access to food). Therefore, much of the debate regarding different policy approaches to agricultural production and food security revolves around a traditional policy dilemma (Timmer, Falcon, and Pearson 1983): high prices to support production or low prices to help consumption. High agricultural prices and food prices should normally lead to more future production, improving future physical availability but making consumption more costly and reducing economic access. The reverse is true for low agricultural prices and food prices, which would worsen availability but improve economic access.

Therefore, in the short run, high food prices benefit producers (all other things being equal), while low food prices help consumers. But in the medium to long term, high food prices may positively affect even net food buyers if higher food prices generate dynamic economic processes that raise employment rates and/or wages (in both rural and urban areas) by amounts that more than compensate for the greater cost of food. Ivanic and Martin (2014) and Headey (2014) have discussed the different short-, medium-, and long-term impacts of price changes. For example, higher agricultural and food prices may lead to increased investments by the private and public sectors in agricultural production and in rural areas; this positively affects employment and wages. If, as argued in various studies, growth in agricultural (and food) production has a large and positive multiplier effect on the rest of the economy (Haggblade and Hazell 2010; Haggblade, Hazell, and Reardon 2007), and appears to be more effective than growth in other sectors at reducing poverty (Christiaensen, Demery, and Kuhl 2010; Eastwood and Lipton 2000), then higher agricultural and food prices do not generally pose a dilemma in policymaking because they lead to more employment opportunities and higher wages, particularly for lower-income producers and workers. There may also be some positive dynamic effects if a policy leads to investments in productivity, thereby reducing production costs and prices in the medium term, even though it increases food prices in the short term.

The opposite may also happen: farmers shielded by highly protective policies and pampered by subsidies that increase the price of the products they sell may not need to invest to maximize profits; therefore, protection and subsidization may lead to fewer investments and lower productivity (see, for instance, Fan 2008; Mogues et al. 2012; Allcott, Lederman, and López 2006). Also, higher agricultural and food prices may increase wages and production costs in other productive activities. Consequently, their external and internal competitiveness may be affected, leading to an overall reduction in domestic production and employment (see Diaz-Bonilla 2015).

Both high prices and low prices result in supply and demand adjustments if markets operate normally and if price signals are transmitted properly to producers and consumers. Higher prices should eventually lead to higher production and lower consumption; both effects would push prices lower (and vice versa, in the case of lower prices).

Those who take the perspective of poor producers prefer high food and agricultural prices, arguing that the agricultural sector's multiplier effect has important benefits for employment and poverty alleviation; a small subset of those analysts gravitate toward protection and price support through government policies. Those who take the perspective of poor consumers emphasize the importance of low food prices because of their positive effect on urban and rural poverty and malnutrition. They usually suggest lower levels of protection and consider the use of some types of consumption subsidies. But governments need to take into account the welfare of both producers and consumers when considering the short-term impacts as well as the medium- to long-term dynamic effects. 
This policy dilemma has led to a variety of policies in developing countries, with very mixed results. A government might try to keep food prices high for producers and low for consumers through subsidies and market interventions. However, the developing countries that have tried such an approach usually find the policies unsustainable due to fiscal costs, the price distortions generated in production and trade, and the inequitable distribution of costs and benefits.

\section{Price Volatility}

The debate about price volatility differs from the previous discussion on price levels. Some experts have argued that price instability generates uncertainties about the true price level for producers and consumers, and therefore production and consumption decisions may lead to suboptimal outcomes compared with those attained under more stable price conditions. For producers, price volatility may reduce investments and cause production to shift toward lower-risk, but also less productive, technologies (although the World Bank [2005] estimated that these effects may not be significant). High and variable food price inflation and price spikes affect consumers negatively because of reduced or uncertain access to food. This is particularly true for poor and vulnerable households, whose incomes do not adjust with inflation and which do not have assets to stabilize their consumption patterns.

There may also be negative macroeconomic impacts, such as balance-of-payments problems, public deficits, and declining total investment because of uncertainty-all of which may have secondround effects on poverty and food security as well (Timmer 1989). It is also important to consider the political impacts - an increase in food prices could lead to social unrest and riots. However, some have noted that high price shocks (spikes), which are only one form of (asymmetric) volatility, rather than volatility in general, seem to motivate political riots and unrest (see Barrett and Bellemare 2011). Persistent food inflation also tends to generate political problems, but in many cases sustained inflation (in contrast with price shocks) is the result of macroeconomic difficulties that may not be related to developments in food markets. ${ }^{1}$

It is therefore crucial to define stability and volatility, which are opposites of each other. In the context of monetary policies, the idea of price stability has usually been interpreted as inflation in the range of 0-2 percent per year. However, more recently, when evaluating policies to confront the effects of the 2007-2008 financial crisis, some observers suggested that price stability could be redefined as annual inflation that does not exceed 4 percent (Blanchard, Dell'Ariccia, and Mauro 2010). "Stable" annual inflation of 2 percent means that the nominal price level is permanently increasing. For example, at 2 percent annual inflation, the price level will increase almost 50 percent in nominal terms in 20 years; at 4 percent, the price level will more than double over the same period. In other words, stability in price levels and stability in the rate of change of those price levels (that is, stability of inflation) are two different concepts.

In the case of food and agricultural prices, the notion of stability for producers refers mainly to price levels, while for consumers the main problems are associated with high and persistent food price inflation.

When considering stability of price levels, it is important to distinguish between the trend, potential changes in that trend because of the emergence of a new trend, and some definition of variability or volatility around those trends. The last concept, in turn, may include both a reasonably smooth business-cycle movement and shorter-term volatility surrounding the business cycle, which may or may not reach extreme values (such as in the case of price spikes or crashes). Smooth and predictable price movements that are part of the economic business cycle (as in the case of macroeconomic models of inflation that consider the gap between actual and potential gross domestic product [GDP]) could perhaps be anticipated. In this case, such variability may be incorporated ex ante into economic decisions. Further volatility, in excess of the trend and cyclical movements, tends to have a shorter duration and may cause

\footnotetext{
${ }^{1}$ Hazell, Shields, and Shields (2005) argue that a nontrivial part of domestic price variability in agricultural and food products is related to macroeconomic factors (see also Dorosh, Robinson, and Ahmed [2009], and Rashid and Lemma [2011] in the case of Ethiopia).
} 
price shocks, leading to prices falling outside the range of trends or normal cycles, depending on the time horizon utilized. These extreme price events may be defined by their frequency (for example, those that happen only 10 percent of the time historically) or by their magnitude (those that drastically deviate from the trend, such as by multiples of the standard deviation). These extreme price events are usually unanticipated, and they may cause economic and political disruptions.

In summary, not all types of what is commonly called volatility are the same, or have the same effects on production and consumption decisions; therefore, it is necessary to differentiate between price trends, their potential changes, business-cycle variability around those stable or changing trends, and shorter-term variability, particularly in the event of extremely high prices (spikes) or extremely low prices (crashes). 


\section{DIFFERENT MEASURES AND CONCEPTS OF TRENDS AND VOLATILITY}

Before determining how to define trends and volatility, it is necessary to discuss several data and measurement issues related to the variables of interest (here, food prices).

\section{Prices in Real or Nominal Terms}

The first question is whether trends and volatility are to be analyzed in nominal prices or in real (also called constant or inflation-adjusted) prices. In the case of the latter, an appropriate deflator must be identified, such as the export unit value index (EUVI) for advanced economies, the US Consumer Price Index (CPI), or the US Producer Price Index (PPI).

Figure 3.1 shows the International Monetary Fund (IMF) index for food and beverages in nominal terms ${ }^{2}$ with two different deflators: the EUVI and the US CPI.

Figure 3.1 Food price indexes (in US dollars): Nominal (right axis) and real (left axis) $(2005=100)$

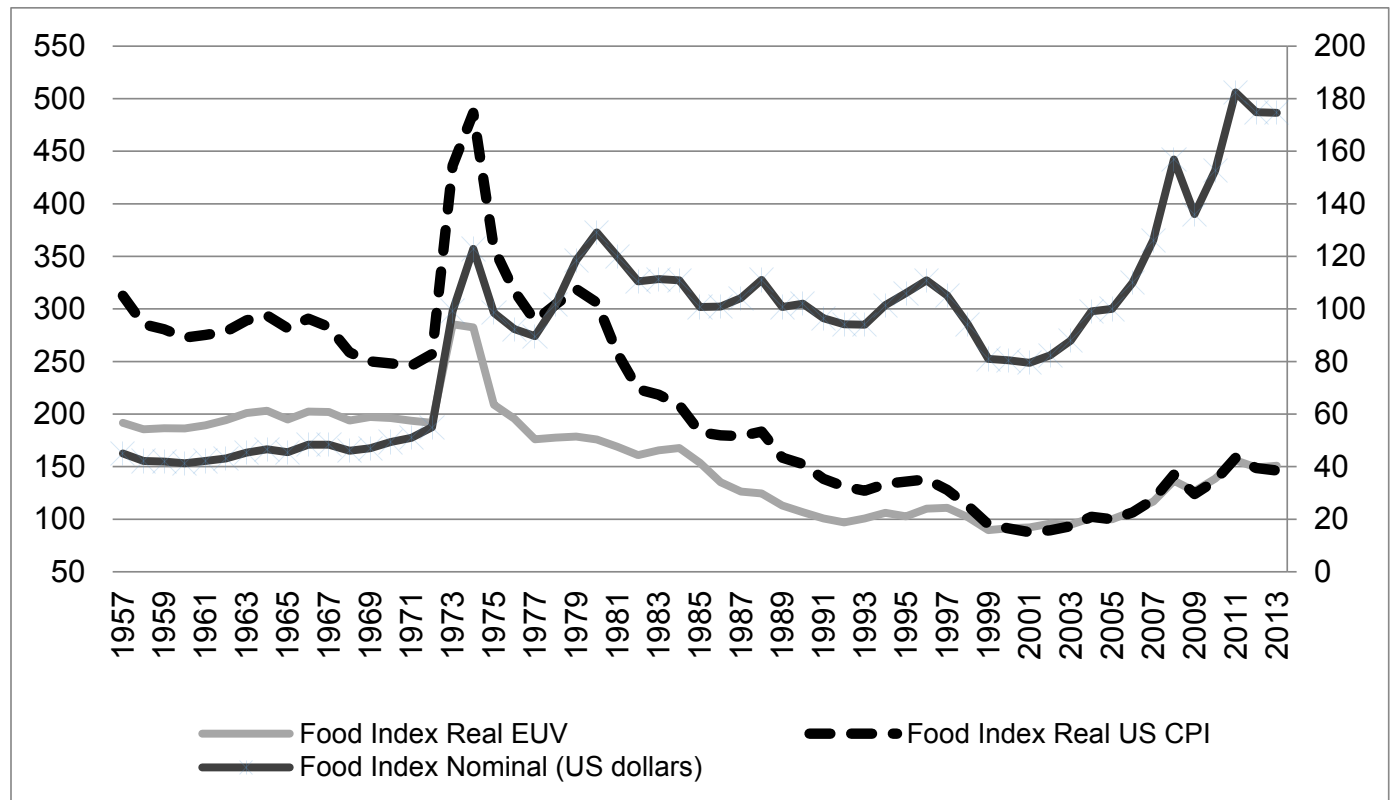

Source: Author calculations based on data from the International Monetary Fund.

Note: $\quad E U V=$ export unit value; CPI = Consumer Price Index.

The behavior of the nominal food index is different from the two real food indexes, which also behave differently from each other.

The nominal index shows a large increase in the early 1970s and then reaches a plateau that lasts until the early 2000s. Then the index experiences another sharp hike, more drastic than the increase in the early 1970 s, and possibly arrives at a new plateau. In the plateau lasting from the mid-1970s to the late 1990 s, the nominal index shows a cyclical pattern and a relatively flat linear trend, with price peaks in 1974, 1980, and 1996. As the nominal index is climbing up to the second plateau, it peaks in 2008 and 2011.

\footnotetext{
${ }^{2}$ The IMF, the World Bank, and the Food and Agriculture Organization of the United Nations (FAO) all calculate food price indexes. They show broadly similar trends, although there are some differences among them due to coverage, the weights used to aggregate the prices of individual commodities, and the representative world prices selected for some of them. It would be useful if the different institutions were to agree on some standard measure. The IMF index is derived from the IMF / International Financial Statistics (IFS) database. The IMF food price index is based on 2005=100 and includes subcategories for the cereal, vegetable oils, meat, seafood, sugar, bananas, and oranges price indexes.
} 
The cyclical pattern during the plateau between 1980 and the mid-2000s appears to be influenced by, among other things, the global business cycle. When the world economy is growing faster, overall income and demand grow as well, and therefore nominal prices go up. The opposite is true when there is slack in the global economy. This is a common pattern identified in the macroeconomic analysis of the business cycle and the behavior of variables such as wages and price (see Rotemberg and Woodford 1999). Figure 3.2 shows the trends (using a Hodrick-Prescott filter) in world growth and food price increases.

Figure 3.2 Trends in world GDP growth (right axis) and in food price nominal inflation (left axis)

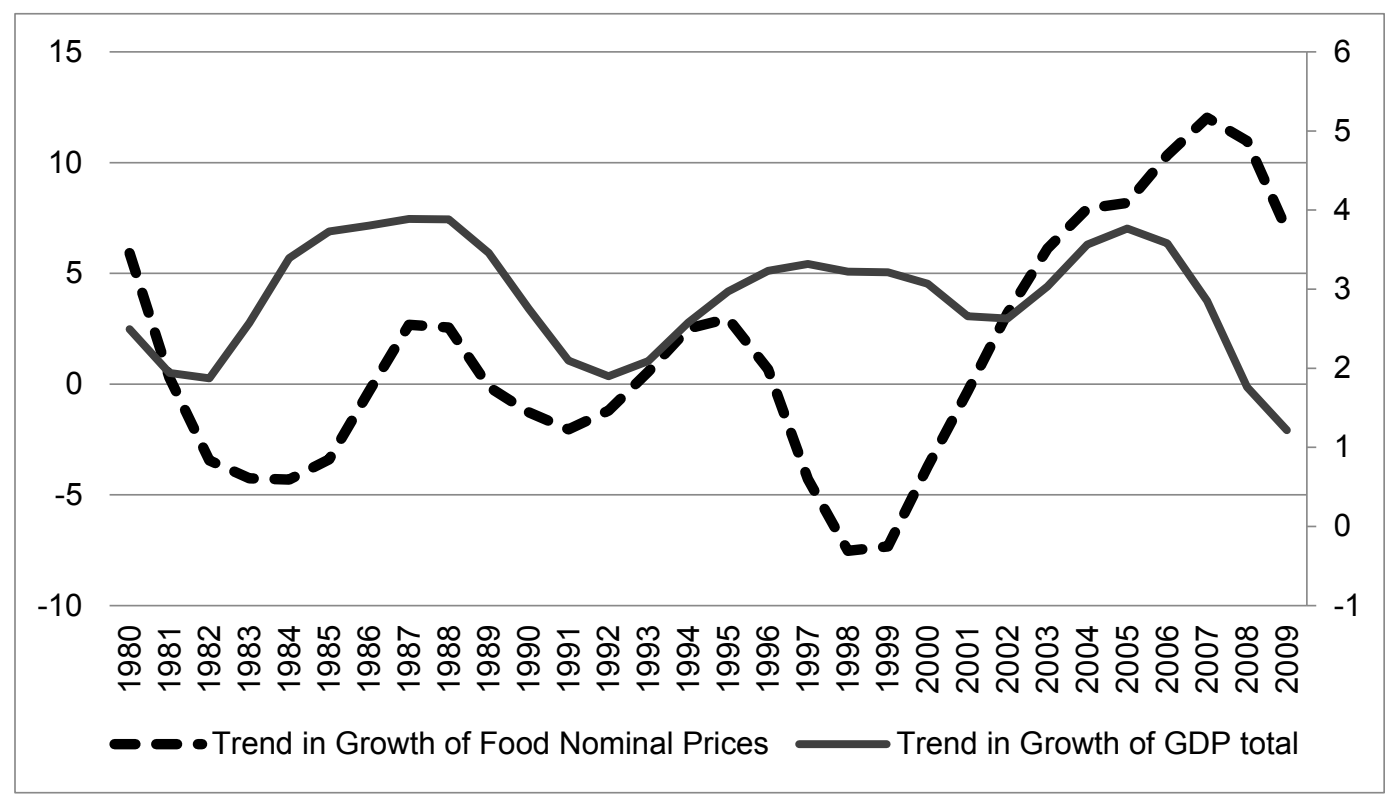

Source: Author calculations based on data from the International Monetary Fund.

The large increase in nominal prices in the first half of the 1970s was not exclusive to food products. Most commodities, including metals and energy, also experienced a nominal price upswing. This suggests a common macroeconomic cause. In this case, the cause was related to the demise of the Bretton Woods monetary system of fixed exchange rates in the early 1970s, whereby the US dollar strongly devalued against gold (see, for instance, Diaz-Bonilla 2010). In the early 2000s, the prices of metals and energy started rising, pushed by global growth and other macroeconomic factors; this was followed by agricultural and food product price increases, mostly in the second part of the decade (DíazBonilla 2010).

The indexes in constant 2005 prices, in contrast, plateau in the 1960s and 1970s, with one peak in 1973-1974 when deflated by the EUVI and two when deflated by the US CPI (a larger peak in 1974 and a smaller one in 1979). Then both indexes show a decline in real terms, but with different patterns of decline. The index deflated by the US CPI shows an earlier and steeper decline compared with the index deflated by the EUVI. Both indexes show a trough in the late 1990s and early 2000s, followed by a moderate recovery. The recovery, however, is clearly of smaller magnitude than the steep increase shown in the nominal index, and these indexes have yet to reach the levels seen in the 1970s. Even the large peaks of the nominal indexes in 2008 and 2011 appear far smaller when expressed in real prices (a discussion of the causes of those patterns can be found in Díaz-Bonilla 2010 and 2015). Since 2011, all indexes, both nominal and real, appear to have reached a new plateau. A key question is what the future trends in nominal and real prices will be from 2015 onward (more on this below). 
Moving the discussion from trends to price volatility, ${ }^{3}$ Table 3.1 shows a common measure of price volatility based on the standard deviation of a series constructed as $\ln p_{t}-\ln p_{t-1}$, where $t$ represents the time period (which may be days, months, years, and so on), $p_{t}$ refers to prices in levels, and ln is the natural logarithm (see, for instance, Gilbert and Morgan 2010; G20 2011). In this case, $t$ is defined as one year, and the table presents the average of the annual standard deviation for each decade. It should be noted that $\ln p_{t}-\ln p_{t-1}$ is an approximation of the growth or changes in prices (which may be also called price "inflation" but could be negative) between two consecutive periods. Therefore, the measure utilized here reflects the volatility of annual price inflation.

\section{Table 3.1 Food price volatility in nominal and real terms}

\begin{tabular}{llll}
\hline Decade & Nominal & Real EUVI & Real US CPI \\
\hline $1960 \mathrm{~s}$ & 3.4 & 2.8 & 3.9 \\
$1970 \mathrm{~s}$ & 21.3 & 17.1 & 21.4 \\
$1980 \mathrm{~s}$ & 6.7 & 5.0 & 7.0 \\
$1990 \mathrm{~s}$ & 7.2 & 6.4 & 6.9 \\
$2000 \mathrm{~s}$ & 9.9 & 6.4 & 9.1 \\
$2010 \mathrm{~s}$ & 10.2 & 7.4 & 9.8 \\
\hline
\end{tabular}

Source: Author calculations based on data from the International Monetary Fund.

Note: $\quad$ EUVI $=$ export unit value index; CPI = Consumer Price Index. The period of the 2010s refers to 2010 to 2014 .

All three variables show that volatility was low in the 1960s when exchange rates were stable; volatility became higher during the multiple macroeconomic, geopolitical, and weather shocks in the 1970s, and then it declined in the 1980s and 1990s (but remained higher than the levels seen in the 1960s). The measured volatility increased somewhat in the 2000s and the first half of the 2010s in the cases of nominal prices in US dollars and real prices when deflated by the US CPI. The index deflated by the EUVI showed no changes in the 2000s and a small increase in the 2010s.

Therefore, Figure 3.1 and Table 3.1 show that it matters whether trends and volatility are expressed in nominal or real terms and which deflator is used.

\section{World Prices: In What Currency?}

As noted above, developments in world macroeconomic conditions need to be considered when analyzing price movements (see, for instance, Diaz-Bonilla 2010, 2015). In particular, exchange rate movements strongly influence nominal world food prices (as in the case of the breakdown of the Bretton Woods monetary system).

Figure 3.3 shows the inverse relationship ${ }^{4}$ between the US dollar (measured as the effective nominal exchange rate against major currencies) and the IMF nominal index of food products. ${ }^{5}$

\footnotetext{
${ }^{3}$ This measure can be applied to any variable and not only prices.

${ }^{4}$ Mundell (2002), among others, pointed out the inverse relationship between the value of the US dollar and the price of commodities in that currency.

${ }^{5}$ The nominal food index is obtained from the IMF/IFS database. The US exchange rate is the index for major currencies in nominal terms calculated by the Federal Reserve. Major currencies include the euro, Canadian dollar, Japanese yen, British pound, Swiss franc, Australian dollar, and Swedish krona. There is also a broader index that considers more than twenty currencies (including the major currencies already mentioned). The indices can be calculated in nominal or in price-adjusted terms. The chart shows the same pattern if presented using the price-adjusted index for the broader set of currencies.
} 
Figure 3.3 Effective nominal US exchange rate (left axis) and nominal food price index (right axis)

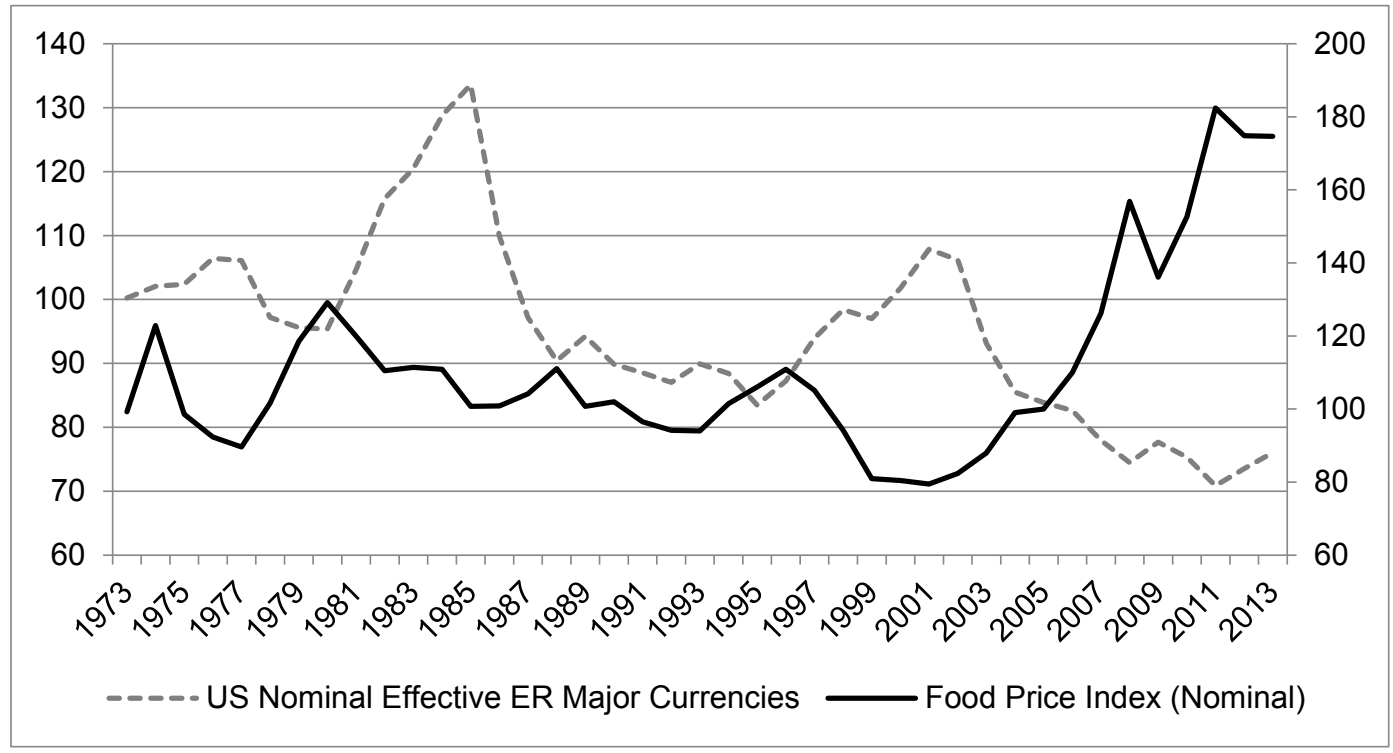

Source: Author calculations based on data from the International Monetary Fund and the US Federal Reserve. Note: $\quad E R=$ exchange rate.

The figure shows that the relative value of the US dollar fluctuated significantly, with peaks in the mid-1980s and the early 2000s, while the nominal food price index moved in the opposite direction. This implies that the currency used must be considered when analyzing food prices.

Figure 3.4 compares the evolution of nominal food price indexes in US dollars and Special Drawing Rights (SDRs), a quasi-currency issued by the IMF. Being a basket of four major currencies (the euro, Japanese yen, pound sterling, and US dollar), SDRs represent a more stable measure of global value than the US dollar alone.

Figure 3.4 Nominal food price indexes in US dollars and SDRs (2005=100 for USD)

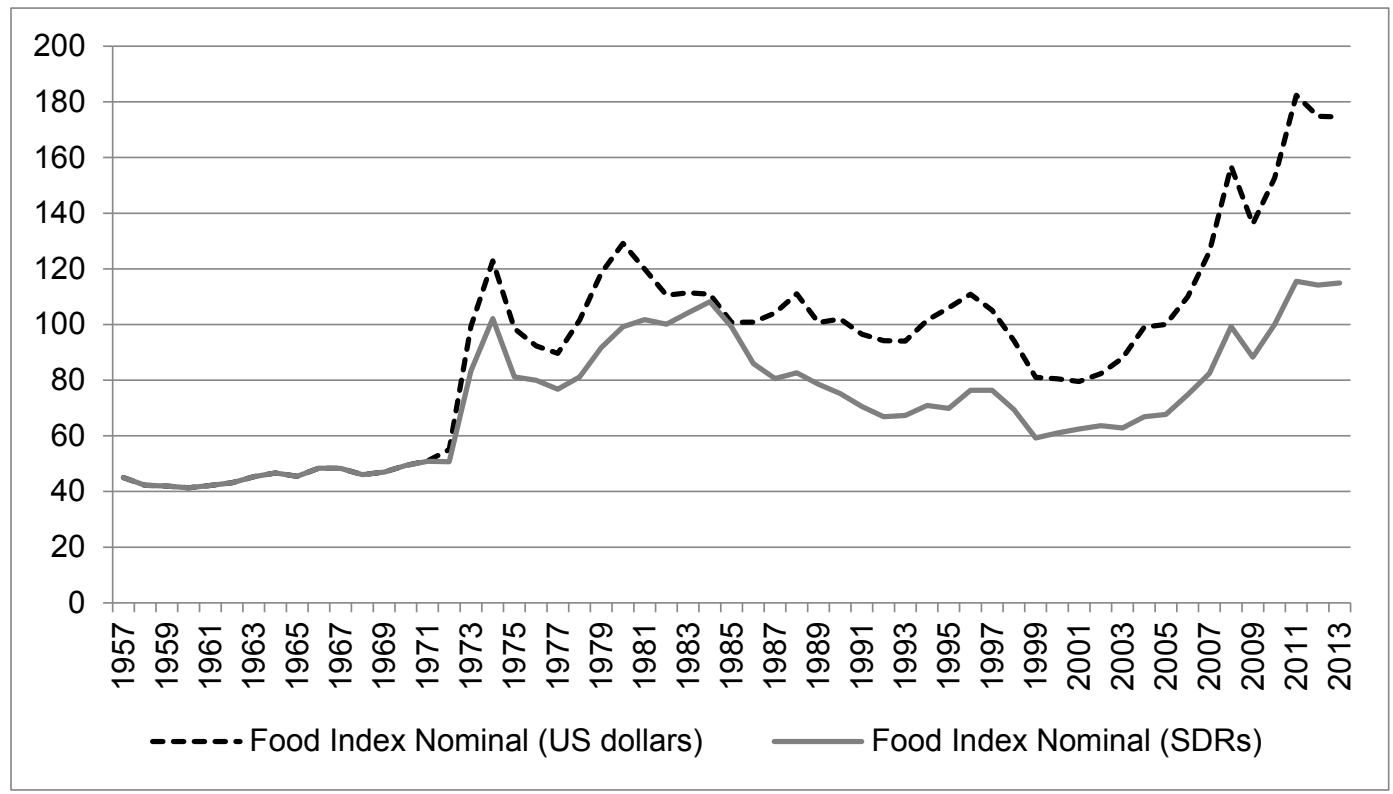

Source: Author calculations based on data from the International Monetary Fund.

Note: $\quad$ SDRs $=$ Special Drawing Rights. 
It is clear that the latest price surge, even in nominal terms, is less pronounced when calculated in SDRs. The 2008 price spike in SDRs is at or below the levels observed in the 1970s and 1980s, while nominal prices in US dollar terms have been above historical averages during the latest price shocks, influenced by the depreciation of the US dollar from its peak in the early 2000 s. Only after the price increase in 2011 does the SDR index move slightly above the values seen in the early 1980s.

Moving to the discussion of volatility, Table 3.2 shows the same measure of volatility as Table 3.1, comparing the nominal price indexes denominated in US dollars and SDRs. Price volatility seems to be much less pronounced when prices are measured in SDR terms than in US dollar terms, suggesting that at least some observed food price volatility is influenced by additional instability in exchange rates, which is affected by other general macroeconomic factors.

\section{Table 3.2 Food price volatility in US dollars and SDRs}

\begin{tabular}{lll}
\hline Decade & SDRs & USD \\
\hline $1960 \mathrm{~s}$ & 3.4 & 3.4 \\
$1970 \mathrm{~s}$ & 18.8 & 21.3 \\
$1980 \mathrm{~s}$ & 6.9 & 6.7 \\
$1990 \mathrm{~s}$ & 7.1 & 7.2 \\
$2000 \mathrm{~s}$ & 8.0 & 9.9 \\
$2010 \mathrm{~s}$ & 8.0 & 10.2
\end{tabular}

Source: Author calculations based on data from the International Monetary Fund.

Note: $\quad$ SDRs $=$ Special Drawing Rights. The period 2010s refers to 2010 to 2014 .

\section{Domestic Prices and World Prices}

In the earlier sections of this paper, the discussion focused on different measures of world food prices. However, food security at the national level is affected by domestic price volatility, which is correlated with world price volatility to different degrees in different countries. Price transmission from international to domestic markets can be limited by various factors such as domestic policies, high transportation costs, limited infrastructure, consumer preferences, and exchange rate variations.

As in the case of world prices, it is important to distinguish between nominal and real prices. The value chain level at which prices are measured also plays a role. Even if global food price changes are transmitted to the domestic economy (defined by some particular market level), their final effect on a consumer will be determined by the degree of integration between the local market in which the consumer participates and the national food market used as the reference. In many developing countries in particular, there are clear distinctions between urban consumers, who may be more integrated with national markets, and rural consumers, who may have weaker links to national markets. Therefore, trends and volatility may differ when considering prices at the farmgate, wholesale, or consumer levels.

\section{Time Horizons}

The discussion of price volatility also requires the definition of a time horizon that is adequate for the purpose of the analysis. For instance, should data be analyzed daily, monthly, quarterly, annually, or at even longer intervals? Using annual values (as this paper has done so far) would obscure shorter-term volatility, as daily, weekly, or monthly price movements may respond to various transitory causes that might cancel each other out during the course of the year. Still, these changes may be relevant for certain economic agents, and their production and consumption decisions, therefore affecting their food security. 
For instance, for consumers who are wage earners, the adequate interval may be a quarter or a month, in line with the timing of salary payments. For producers of annual crops, what matters may be the variability of annual prices, while other producers, such as dairy farmers (who deliver daily), may be affected by shorter-term volatility. The level of development of futures markets and hedging instruments is also important when considering the appropriate frequency of analysis. In poor developing countries, daily and monthly price variability in futures markets does not drastically affect small-scale farmers' decision-making (with regard to crop production and marketing) because they do not have access to the futures markets. In contrast, farmers in more developed countries may use futures market information to enter into different contracts and therefore find volatility information at a daily or monthly interval relevant for their business.

\section{Selection of Food Indexes and Food Items}

The choice of food indexes or food items is another aspect that deserves attention when analyzing food price volatility. This is because the final effect of food price volatility on food security at the national level will depend on the dietary preference of individual countries' populations.

According to the food balance sheets calculated by the FAO (2014), Indonesia is a clear example of the importance of considering country-specific dietary preferences. Rice, a storable product, accounts for around 48 percent of the calories and 40 percent of the proteins consumed on average (using 2009 data; these values were 56 percent and 53 percent, respectively, in 1980). The situation in India is somewhat more diversified than in Indonesia, with wheat and wheat products accounting for 21 percent and rice for about 29 percent of the total calorie intake on average in 2009. In contrast, many African countries have a consumption structure that shows a wider variety of products. For instance, in western Africa, ${ }^{6}$ the average calorie consumption in 2009 was comprised of the following: 5.4 percent wheat and wheat products, 12.6 percent rice, 9.1 percent maize and maize products, 10 percent millet and millet products, 9.1 percent sorghum and sorghum products, 8.7 percent cassava and cassava products, and 7.9 percent yams (see Díaz-Bonilla 2014). ${ }^{7}$

The analysis of price movements may focus only on the most basic food staples (rice, wheat), as they represent an important portion of the dietary requirements in developing countries, especially in the most vulnerable countries. As noted, however, some poor regions depend on multiple products for basic calories. Furthermore, access to a minimum level of food calories is insufficient to achieve food and nutrition security; dietary diversity also plays a role in nutrition security (Arimond and Ruel 2006). Therefore, to more comprehensively analyze the effects of food price volatility, the price evolution of various food items should also be taken into consideration.

Also, if the analysis of price movements focuses on the impact of price volatility on general economic variables at the national level (in contrast to food security concerns), world food indexes, such as those calculated by the IMF (used in this paper), the World Bank, and the FAO, may not reflect the impact of price changes on a specific country because every individual index for those countries would have a specific basket of exports and imports. ${ }^{8}$ Figure 3.5 shows an indicator that better reflects that composition: the terms of trade for different developing regions, corresponding to the median values for 36 countries in Africa south of the Sahara (SSA), 17 in Latin America and the Caribbean (LAC), six in the Middle East and North Africa (MENA), and 12 in Asia.

\footnotetext{
${ }^{6}$ Benin, Burkina Faso, Cabo Verde, Gambia, Ghana, Guinea, Guinea-Bissau, Liberia, Mali, Mauritania, Niger, Nigeria, Saint Helena, Ascension and Tristan da Cunha, Senegal, Sierra Leone, and Togo.

${ }^{7}$ Some of these products, such as cassava and yams, are difficult and costly to store, which limits the use of public stocks for price stabilization.

${ }^{8}$ As noted, the food price indexes calculated by the IMF, the World Bank, and the FAO, although sharing broadly similar trends, are somewhat different. Therefore, while the IMF index shows an increase in nominal prices of about 107 percent between 2003 and 2011, the comparable number is 121 percent for the World Bank and 135 percent in the case of the FAO. As mentioned, it would be useful if the international organizations could adopt a single index.
} 
Figure 3.5 Terms-of-trade index (median value; $2000=100)$

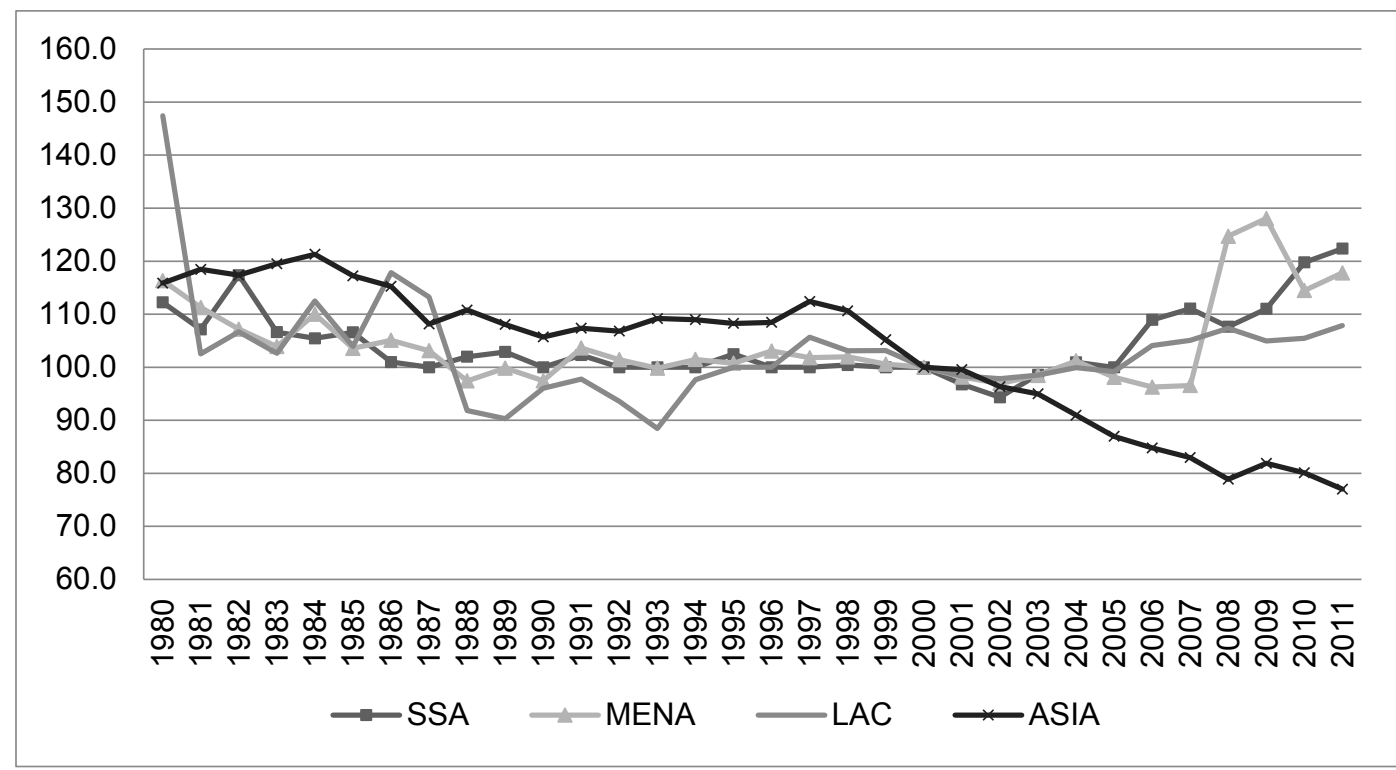

Source: Author's calculations based on World Bank (2014).

Note: This corresponds to the median values for 36 countries in Africa south of the Sahara (SSA), 17 in Latin America and the Caribbean (LAC), 6 in the Middle East and North Africa (MENA), and 12 in Asia.

The terms of trade differ across regions and show different responses even during the price spikes in 2008 and 2011. This indicates that the composition of exports and imports is different for every region. For instance, oil constitutes a great portion of exports in MENA, and metals and oils have a strong presence in SSA; therefore, MENA and SSA saw a larger improvement in their terms of trade than LAC, which has a more diverse export basket. In MENA and SSA, higher food prices were more than compensated for by increases in the prices of other commodities, highlighting the importance of analyzing developments in all commodities at the same time and not focusing on only some of them. In contrast, the developing countries in Asia, whose import structure relies more heavily on commodities, showed a decline in the terms of trade because the price of all commodities (and not only food) increased.

\section{Trends and Volatility: Different Approaches}

As mentioned, a common measure of volatility is the standard deviation of price changes (or inflation) within a specific period, which may be defined in days, months, years, and so on.

It was also noted that $\ln p_{t}-\ln p_{t-1}$ is a proxy for nominal inflation for the period $t$, which is defined as one year in Tables 3.1 and 3.2 (annual inflation). However, monthly inflation is often used (see, for instance, Gilbert and Morgan [2010] and G20 [2011], which use monthly price changes). Some have also argued that using standard deviations of log prices is a better measure than other potential metrics because it avoids the issue of defining trends (Gilbert and Morgan 2010).

In some instances, evaluating this measure of volatility may be enough. However, by not considering trends and changes in trends, observers may miss key elements when analyzing relevant policy responses. In macroeconomics, a few studies have already noted that many crucial variables, such as GDP, seem to exhibit variable trends (see, for instance, Stock and Watson [1988], focusing on the US economy, and Aguiar and Gopinath [2004], analyzing emerging markets). Also, the factors and policies affecting trends and changes in trends are usually different from those affecting the variability around the trends (although there may be cross effects).

If we accept the argument that both the variability of a trend and the variability around those different trends need to be considered separately, then it is crucial to identify methods of decomposing 
price movements into trend variability (explained by long-term factors), variability around the trend (partially related to the business cycle), and shorter-term variability that lies beyond both trends and cycles (which may include extreme events such as spikes or crashes) (see Díaz-Bonilla and Ron 2010; Tadesse et al. 2014). The best method of separating trends and cycles has been long debated in applied macroeconometrics, with different approaches leading to different decomposition results (see, for instance, Canova 1998, 1999, 2007).

The following subsections will first address trends and cycles; then the issue of extreme events will be examined in further detail.

\section{Trends and Cycles}

In relation to trends and cycles, three detrending methods are used to demonstrate the different results that can be obtained from different methods. The three methods are the lineal trend (LT) (Figure 3.6), the Hodrick-Prescott (HP) filter (Figure 3.7), ${ }^{9}$ and the asymmetric Christiano-Fitzgerald (CF) filter (Figure 3.8). ${ }^{10}$

The cycle in each respective figure is obtained by subtracting the value of the trend from the nominal value of $p_{t}$ at the same period $t$.

Figure 3.6 Food price index in nominal US dollars: LT trend and cycle

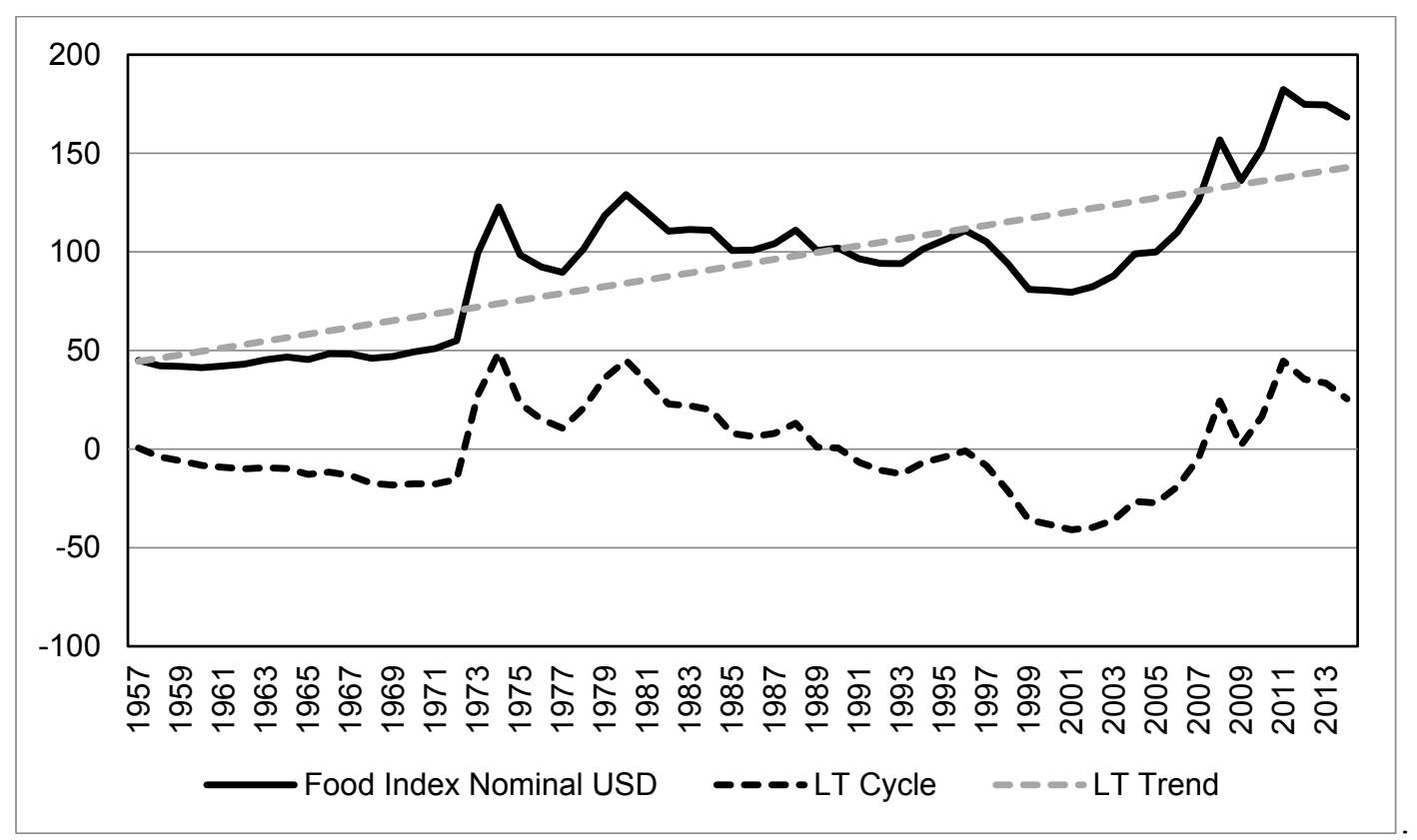

Source: Author calculations based on data from the International Monetary Fund.

Note: $\quad$ LT $=$ lineal trend method.

\footnotetext{
${ }^{9}$ The HP filter is calculated with a lambda of 100 . Compared to the CF, the HP does not capture the turn at the end toward a plateau.

${ }^{10}$ The CF filter is the full sample asymmetric specification with the underlying variable considered to be nonstationary (as indicated by the tests on the nominal food price index) and cycle periods between two and eight years. This specification allows the values at the beginning and end of the time series to remain in the calculations. In contrast, other band-pass filters with fixed lags lose the values at the extreme ends of a time series because of the lags. As noted, the HP filter also has problems capturing the trends at the beginning and end of a series. The advantages and limitations of the filters, neither of which is perfect, are discussed in detail in Canova 2007. Canova 1998 also gives a more detailed comparison of different detrending methods using macroeconomic series.
} 
Figure 3.7 Food price index in nominal US dollars: HP trend and cycle

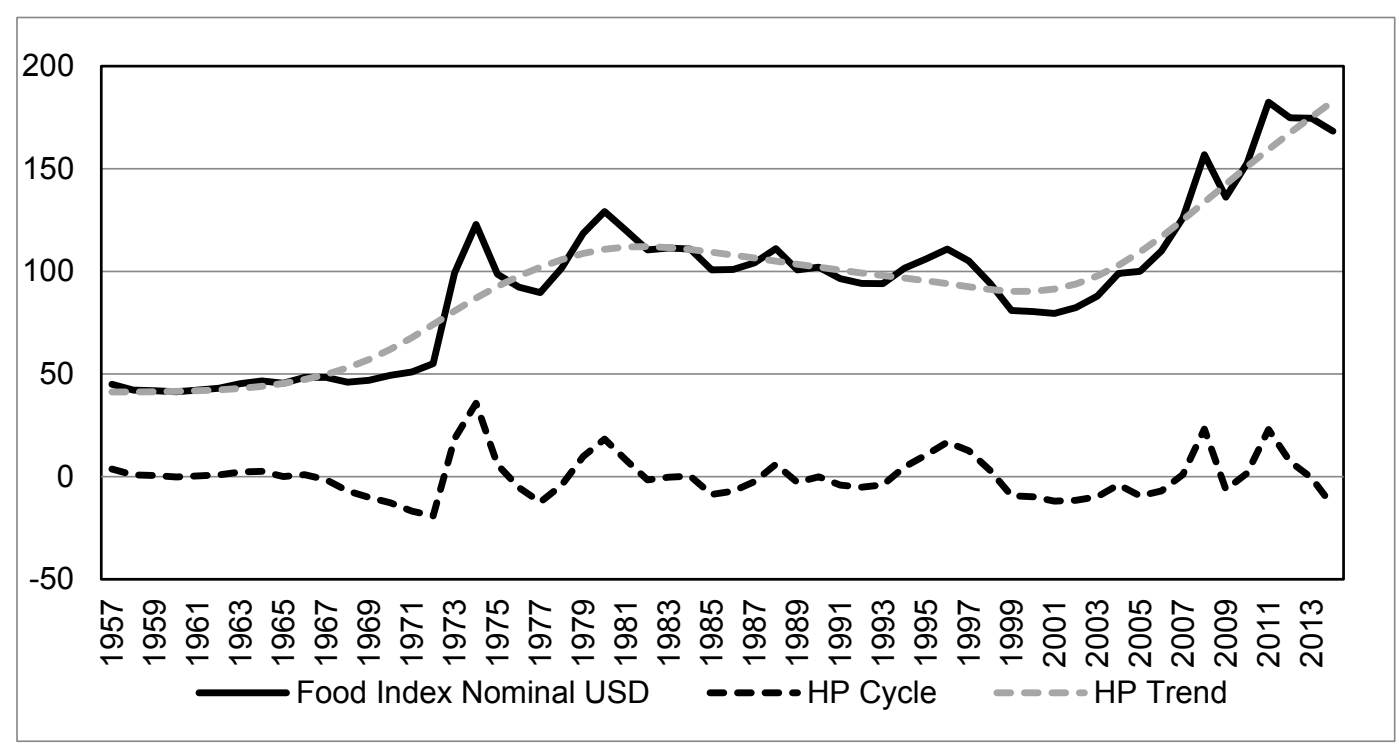

Source: Author calculations based on data from the International Monetary Fund.

Note: $\quad H P=$ Hodrick-Prescott filter.

Figure 3.8 Food price index in nominal US dollars: CF trend and cycle

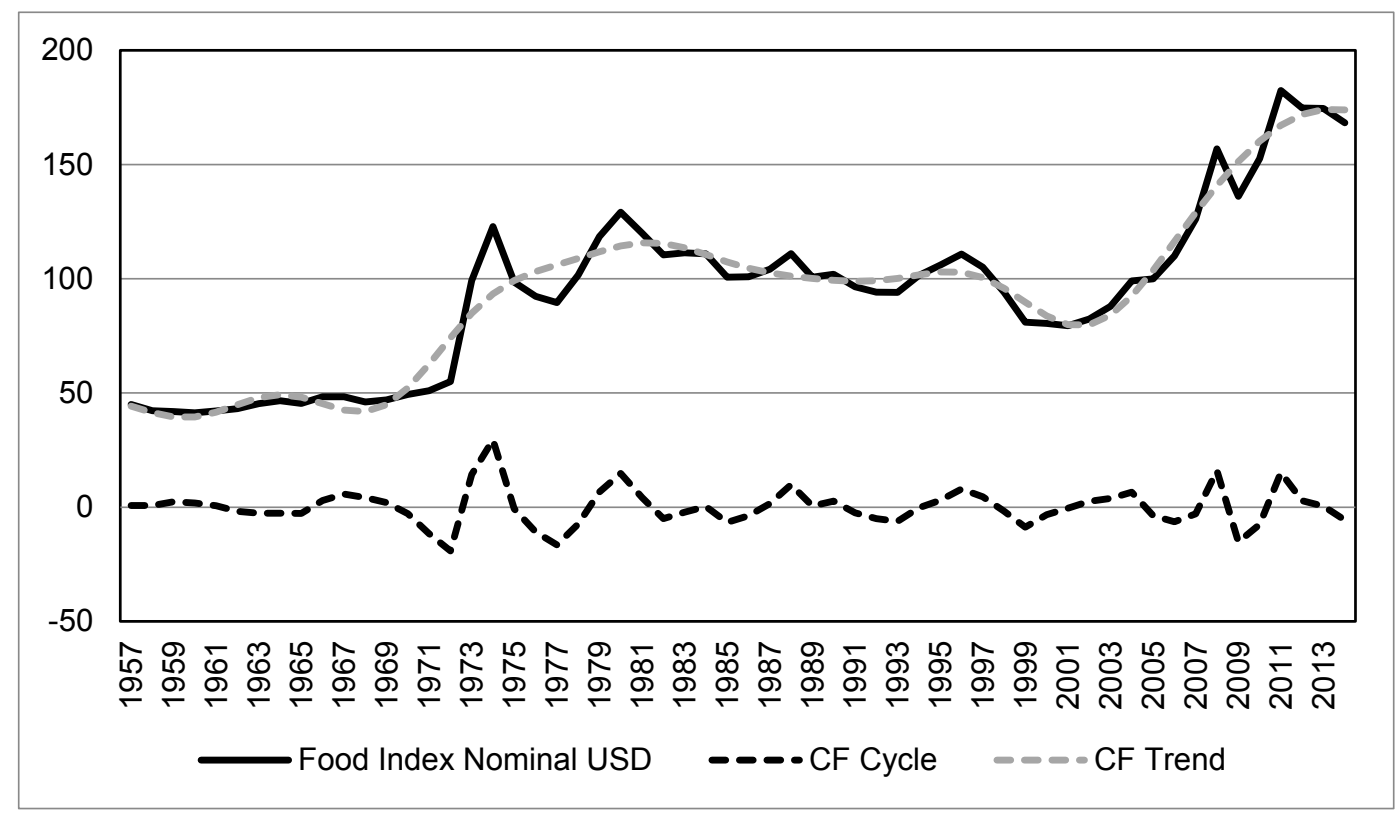

Source: Author calculations based on data from the International Monetary Fund.

Note: $\quad \mathrm{CF}=$ Christiano-Fitzgerald filter.

Several observations can be made about the figures above. First, regardless of the method applied, the price volatility seen between the late 1950s and the first half of the 1970s is lower than in the rest of the series. Second, the LT has the problem of being constant during the period considered, even though tests have shown ${ }^{11}$ that there were structural breaks in the trend. Both the HP and CF filters are

\footnotetext{
${ }^{11}$ A simple test, not shown here, was conducted on the stability of the coefficient of a trend variable with the following
} 
able to capture changes in trends, although they show slightly different results. There are no conclusive tests to determine which method has captured the "correct" trend. Third, the HP filter, which usually has problems detecting changes at the end of a series, signals a continuation of the upward trend, while the CF filter is already pointing to an inflection point in the upward movement. Fourth, all the methods show larger increases in the mid-1970s than in the more recent price spikes. Finally, the CF filter considers the trough in the 1990s as a change in trend, while the LT and, to a lesser extent, the HP filter evaluate the period as a down cycle.

Table 3.3 presents a measure of volatility different from the one shown in Tables 3.1 and 3.2. Here, volatility is calculated as the decade average of the percentage deviation (in absolute values) of the food price index from the trends calculated using the LT, HP, and CF methods. ${ }^{12}$ For comparison, the table also includes the measure of volatility without the trend that is shown in Tables 3.1 and 3.2 (called "StDev of LN Prices" here).

Table 3.3 Different indicators of volatility

\begin{tabular}{lllll}
\hline Decade & HP & CF & LT & StDev of LN Prices \\
\hline $1960 \mathrm{~s}$ & 5.1 & 6.1 & 20.6 & 3.4 \\
$1970 \mathrm{~s}$ & 17.2 & 13.8 & 31.1 & 21.3 \\
$1980 \mathrm{~s}$ & 5.1 & 4.5 & 20.4 & 6.7 \\
$1990 \mathrm{~s}$ & 7.4 & 4.3 & 9.6 & 7.2 \\
$2000 \mathrm{~s}$ & 8.7 & 5.2 & 20.8 & 9.9 \\
$2010 \mathrm{~s}$ & 5.6 & 3.8 & 22.4 & 10.2 \\
\hline
\end{tabular}

Source: Author calculations based on data from the International Monetary Fund.

Note: $\quad \mathrm{CF}=$ Christiano-Fitzgerald filter; $\mathrm{HP}=$ Hodrick-Prescott filter; $\mathrm{LN}=\log$ normal; $\mathrm{LT}=$ lineal trend; $\mathrm{StDev}=\mathrm{standard}$ deviation.

First, using a fixed trend for the whole period (LT) leads to higher estimates of volatility (a loglinear trend would produce qualitatively similar results). Second, all the measures of volatility indicate higher volatility in the 1970s. However, to the extent that the HP and CF filters allow for the extraction of trends, the implied volatility around those trends is lower than in the case of "StDev of LN Prices." This last measure basically uses a different lineal trend for every decade (the average for the period), which, although it avoids the LT problem of applying the same lineal trend for several decades, will still not capture changes in trends occurring within a decade. Third, as an extension to the previous point, because food prices increased at a slower rate in the 2000s than in the 1970s, the HP filter and particularly the CF filter regard part of the total volatility calculated using "StDev of LN Prices" as changes in trend.

In summary, it is important to keep in mind that for any kind of analysis of price series, assumptions about trend behavior and the corresponding detrending method will affect the conclusion regarding price variability. When using measures that ignore trends, changes in underlying trends (which are usually related to more permanent factors) may be wrongly characterized as changes in volatility. Also, policies that address changes in underlying trends are different from those used to confront changes in volatility.

equation: $Y(t)=a+b^{*} y(t-1)+c^{*}$ lineal trend. $Y(t)$ is the nominal index for food prices, in both original value and log form. Tests on the coefficient $c$ of the lineal trend variable showed structural breaks both in cases of prices in normal values and in natural logs.

${ }^{12}$ The calculation for Table 3.3 is as follows: First, calculate $(y(t)-\operatorname{trend}(t)) / \operatorname{trend}(t)$; $t$ is defined as one year. This is the value of the deviation from trend, which is then expressed as a percentage of the trend. Second, take the absolute value of that percentage for every year. Third, calculate the average for the decade. Conceptually, this is similar to the coefficient of variation calculated as the standard deviation of a variable divided by the average of that variable over a certain period. The main difference between the measure utilized in this paper and the concept mentioned in the previous sentence is that in the latter, the trend is assumed to be a flat lineal value for the period, while in Table 3.3 the trend may be changing during that period. 


\section{Shorter-Term Variations}

Until now, the discussion has focused on trends and cycles. However, as already noted, different forms of volatility are conflated in the measure that uses the standard deviation of inflation (that is, the difference of prices in logs). An increase in volatility measured this way may be due to (1) changes in the longerterm trend, (2) a medium-term cycle, or (3) shorter-term volatility, which in some cases may reach the level of extreme events. Points 1 and 2 have already been discussed in the previous sections. Identifying short-term volatility is also a topic relevant to policymaking, particularly if volatility reaches the level of an extreme event.

Policymakers must understand the causes of an extreme price event in order to design an appropriate policy response, and this requires differentiating between the three elements of volatility mentioned above. For instance, the policy approach to changes in price trends (point 1), linked to significant long-term modification of underlying income growth and demographic trends, may be different from the policy approach to demand-side macroeconomic forces driving the business cycle (point 2). Weather problems, sudden changes in trade policies of systemically important countries, and abrupt shifts in financial conditions (all of which would affect short-term volatility in prices) may require yet other policy approaches. However, as before, in decomposing the three aspects (trends, cycles, and shorter-term variations) analysts face the problem of how to differentiate them.

Figure 3.9 presents a possible decomposition using the HP filter (for another approach to the decomposition, see Tadesse et al. 2014).

\section{Figure 3.9 Trends, cycles, and spikes in food prices}

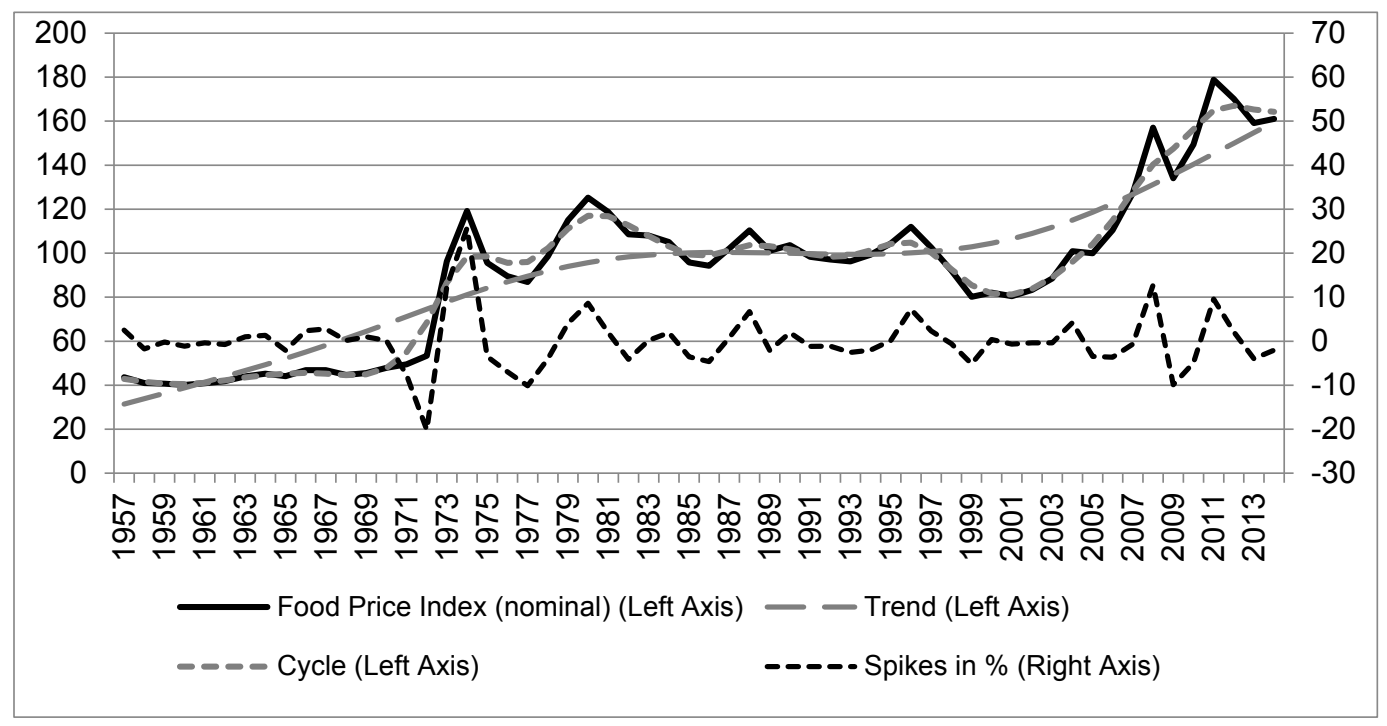

Source: Author calculations based on data from the International Monetary Fund.

The smoothness of the variable resulting from the HP filter can be modified using different values of the penalty parameter (let us call it lambda) in the HP optimization algorithm. Applying the HP to a variable, the larger the lambda value, the smoother the series is; if lambda approaches infinity, the series is a lineal trend. Here, a lambda value of 100 is used for calculating the trend, and 6.25 for the cycle (see Ravn and Uhlig [2002] for a discussion of how to adjust the HP filter). Then short-term volatility is the difference between the actual price $p_{t}$ and the value of the HP filter at $t$ representing the business cycle level, expressed as a percentage of the value of the HP filter representing the trend level.

In the 1970s, the breakdown of the Bretton Woods system of exchange rates and a series of supply and demand shocks led to a steep upward adjustment in the nominal prices of food and other commodities. From then until the mid-2000s, nominal food prices oscillated around that new plateau, in 
part affected by the global business cycle (as already discussed). Nominal prices bottomed out between the late 1990s and early 2000s, a period in which price declines were deeper and more extended than the previous lows. This was the result of a series of financial crises - starting with the 1997 Asian financial crisis and ending with the 2002 Argentine crisis-which reduced demand and/or increased the supply of food (and commodity) products. The early 2000s saw the decline in global growth and the last cycle of the US dollar peaking (see the discussion about the macro factors in the 1970s and the 2000s in DíazBonilla $[2008,2015])$. Until about 2005, however, the nominal increase was in line with previous nominal cycles.

In the second part of the 2000s, at least two developments must be considered: the price trend was moving upward after hitting a nominal bottom in the late 1990s and early 2000s, and price spikes occurred in 2008 and 2011. As discussed in another study (see Díaz-Bonilla 2010), the peak of the 2008 spike was smaller, and reaching it took a longer period of time, when compared with the spike in the early 1970s. In the 1970s, there was an almost 200 percent increase in the index of nominal food prices in about five years, while in the 2000 s the increase was less than 140 percent over almost nine years. If extreme high-price events are defined as those being more than two standard deviations from the average, only the price spikes in 1974 and 2008 can be considered extreme price events (the 2011 shock was less than two standard deviations from the average). Figure 3.9 also shows the smaller food price spikes in the late 1970s (related to the second oil shock) and in the second half of the 1980s and mid-1990s (more related to weather events) (see Díaz-Bonilla 2010).

The decomposition performed in this paper points to a component of that volatility: the potential change in the medium-term trends of nominal and real prices. Having reached another plateau in the 2010 s, nominal food prices may remain at that level (with likely fluctuations similar to those seen as prices reached the plateau in the 1970s). However, if nominal prices stay at the new plateau with oscillations, real prices will decline. This would imply a reverse in the small upward trend shown in Figure 3.1, probably returning to the long-term decline in real terms experienced since the 1980s (a discussion of scenarios can be found in Díaz-Bonilla et al. [2014] and Díaz-Bonilla [2015]). The analysis of changes in these medium- to longer-term events requires the variability of trends to be disentangled from the cyclical and temporary components of overall price volatility.

\section{Expected and Historical Volatility}

All the measures of volatility discussed so far have been based on historical data, which are the actual realization of the variables of interest. However, economic agents base their decisions on the expected value of the relevant variables, in this case food prices (Torero 2012). The expected values may be based on some backward-looking and adaptive rules of thumb or on more sophisticated modeling of future scenarios. In the case of commodities with futures markets, volatility can be calculated using futures prices; only in the case of perfect foresight, however, would ex post realized values of prices and their volatility coincide with ex ante expected values.

Furthermore, in this line of analysis, it can be argued that "true" volatility (the expected volatility) in the context of economic decisions is only the difference between the expected price at time $t+1$ that is forecasted at time $t$ and the realized price at time $t$. In contrast, the difference between the expected price at time $t+1$ that is forecasted at time $t$ and the realized price at time $t+1$ is the unexpected volatility, which by definition is not included in a farmer's economic decisionmaking. In turn, these two measures are different from calculations based on the realized price difference between $t$ and $t+1$. Therefore, according to this view, the expected prices should be first estimated when calculating volatility. This opens the broader issue of how expectations are formed and modeled, which will not be discussed here (see, for instance, Triantafyllou, Dotsis, and Sarris 2013). 


\section{Scaling the Shocks}

This paper has not yet discussed the impact of price changes on countries, producers, and consumers. Analyzing this impact requires not only proper characterization of trends and volatility; the relevant shocks must also be properly scaled by macroeconomic variables such as GDP, exports, or fiscal accounts (at the country level) and household income or consumption (at the producer and consumer levels). A series of studies conducted by Bela Balassa in the early 1980s to analyze different global economic shocks in the 1970s, including the price events during that period (see Balassa 1984, 1986), is an example of such scaling at the country level.

In the case of food prices, a possible indicator of the size of a price shock at the country level may be obtained by dividing food imports by total exports (that is, how much of the income from all exports a country needs to pay for the food import bill). This seems to be a better proxy for affordability and the potential burden on the balance of payments at the national level than other indicators, such as the net food trade position (Díaz-Bonilla et al. 2000). ${ }^{13}$ Figure 3.10 presents this indicator evaluated with data on the agricultural products (a broader category than food products alone) of several aggregates of countries: least developed countries (as defined by the United Nations), net food importing countries (as defined by the World Trade Organization, with some implications on trade negotiations) and low-income fooddeficit countries (a category defined by the FAO).

\section{Figure 3.10 Agricultural imports as percentage of total merchandise exports}

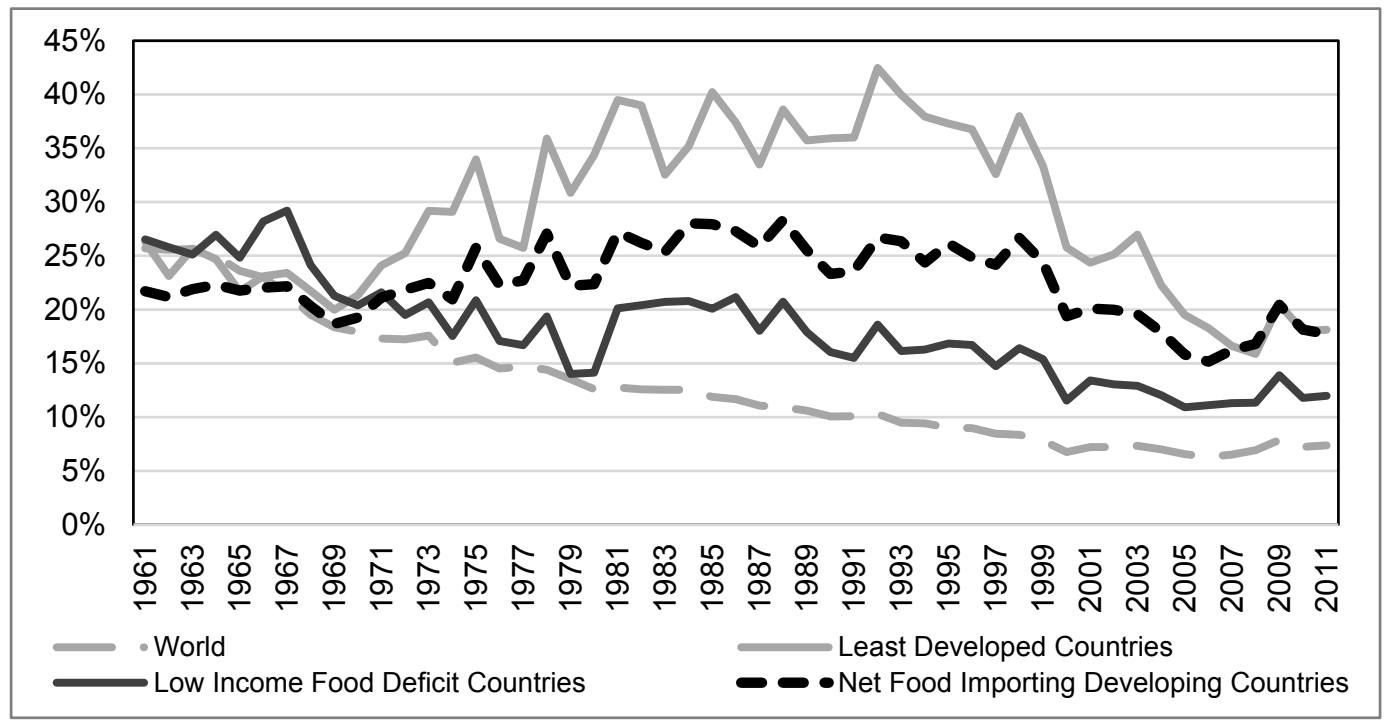

Source: Author calculations based on data from the Food and Agriculture Organization of the United Nations.

The price shock in the 1970 s clearly affected those groups of countries more than the 2008 price shock (at the time of this writing, data for 2012 were still unavailable; therefore, the effects of the 2011 shock cannot be evaluated). Of course, this indicator should also be calculated at the country level and not only for aggregates of countries.

${ }^{13}$ Like any other indicators, this indicator has its limitations. First, it reflects not only food prices but also other price and income effects on food imports and total exports. Also, in theory, if quantities of food imports decline significantly because of high international prices, the indicator may not change at all, but domestic prices and welfare would still be affected. It should, however, be noted that food items are usually relatively price inelastic. Furthermore, at the level of aggregation of total food imports, results are even more muted because of substitution effects across different items. For instance, in the case of least developed countries as a whole, quantities of food imports declined by 1.3 percent in 2008 when compared with 2006, while world food prices increased by about 33 percent during the same period, according to the IMF index. This translates into an uncompensated point elasticity of about -0.04 between those years. Finally, it should be noted that the ratio in Figure 3.10 is not used as a welfare indicator; rather, it is a proxy for the economic burden of high food prices at the balance-of-payments level. 


\section{CONCLUSIONS}

This paper has argued that analysis of volatility can benefit from differentiating between trends, cycles, and shorter-term events. And if this is true, it is important to clarify how trends are defined and measured and whether shocks can fall outside a "normal range" (this also requires "normal" to be defined).

Different approaches to tackle those issues were discussed.

Regardless whether price data are decomposed into trends, cycles, and shorter-term events, various data issues should be considered when analyzing volatility, including whether prices are measured in world or domestic markets. If the focus is on world prices, it is then necessary to define the currency of quoted prices (such as US dollars, euros, SDRs, and so on). If a volatility analysis is centered on domestic prices, then the markets relevant to price formation and measurement must be identified along the value chain (production, processing, and distribution) that links the primary producers to final consumers. It is also important to clarify whether volatility is analyzed using nominal prices or real prices; in the latter case, an appropriate deflator must be identified (such as the EUVI for advanced economies, the US CPI, or another nominal index). In addition, it is crucial to identify whether the analysis focuses on specific commodities or broader aggregates of commodities. Finally, it is necessary to explicitly define the time period when determining volatility. Whether the appropriate time period is annual, seasonal, monthly, or even daily depends on the purpose of the analysis. For instance, if the analysis focuses on consumers, the time period may be shorter (say, monthly) than when the analysis focuses on producers. This is because producers make decisions based on longer time frames (at least yearly for planting decisions for many crops and even longer for investment decisions).

Irrespective of how volatility is defined and measured, identifying its impact on nations, producers, and consumers requires (1) proper scaling of changes in prices; (2) a systemic view of trends, cycles, shocks, and crises; and (3) consideration of all macroeconomic cross effects (fiscal, monetary, inflation, exchange rates) of increases in all commodity prices (not only food) and other world variables (such as in Balassa 1984, 1986).

The price shocks in 2008 and 2011 focused the attention of the public and policymakers on price volatility, but the results obtained from decomposing data into trends, cycles, and shorter-term volatility also suggest that there is a need to determine whether price variations are responding to cyclical and shorter-term movements or whether they are the result of a changing trend reflecting adjustments in longterm fundamentals that need to be properly understood. 


\section{REFERENCES}

Aguiar, M., and G. Gopinath. 2004. Emerging Market Business Cycles: The Cycle Is the Trend. NBER Working Paper 10734. Cambridge, MA, US: National Bureau of Economic Research.

Allcott, H., D. Lederman, and R. López. 2006. Political Institutions, Inequality, and Agricultural Growth: The Public Expenditure Connection. Washington, DC: World Bank.

Arimond, M., and M. Ruel. 2006. "Dietary Diversity Is Associated with Child Nutritional Status: Evidence from 11 Demographic and Health Surveys." Journal of Nutrition 134: 2579-2585.

Balassa, B. 1984. “Adjustment Policies in Developing Countries: A Reassessment.” World Development 12 (9): 955-972.

. 1986. "Policy Responses to External Shocks in Developing Countries." American Economic Review 76 (2): $75-78$.

Barrett, C., and M. Bellemare. 2011. The G-20's Error: Food Price Volatility Is Not the Problem. Ithaca, NY, US: Cornell University Press.

Blanchard, O., G. Dell'Ariccia, and P. Mauro. 2010. Rethinking Macroeconomic Policy. IMF Staff Position Note 10/03. Washington, DC: International Monetary Fund.

Canova, F. 1998. “Detrending and Business Cycle Facts.” Journal of Monetary Economics 41: 475-540.

. 1999. "Does Detrending Matter for the Determination of the Reference Cycle and the Selection of Turning Points?" Economic Journal 109 (452): 126-150.

2007. Methods for Applied Macroeconomic Research. Princeton, NJ, US: Princeton University Press.

Christiaensen, L., L. Demery, and J. Kuhl. 2010. The (Evolving) Role of Agriculture in Poverty Reduction. UNUWIDER Working Paper 2010/36. Helsinki, Finland: United Nations University, World Institute for Development Economics Research.

Díaz-Bonilla, E. 2010. "Globalisation of Agriculture and Food Crises: Then and Now." In Food Crises and the WTO, edited by B. Karapinar and C. Häberli. Cambridge, UK: Cambridge University Press.

2014. On Food Security Stocks, Peace Clauses, and Permanent Solutions after Bali. IFPRI Discussion Paper 01388. Washington, DC: International Food Policy Research Institute.

2015. Macroeconomics, Agriculture, and Food Security: An Introductory Guide for Policy Analysis in Developing Countries. Washington, DC: International Food Policy Research Institute.

Díaz-Bonilla, E., and J. Ron. 2010. Food Security, Price Volatility and Trade: Some Reflections for Developing Countries. ICTSD Programme on Agricultural Trade and Sustainable Development Issue Paper 28. Geneva: International Center for Trade and Sustainable Development.

Díaz-Bonilla, E., E. Saini, B. Creamer, G. Henry, and E. Trigo. 2014. Global Strategic Trends and Agricultural Research and Development in Latin America and the Caribbean: A Framework for Analysis. Cali, Colombia: Centro Internacional de Agricultura Tropical.

Díaz-Bonilla, E., M. Thomas, S. Robinson, and A. Cattaneo. 2000. Food Security and Trade Negotiations in the World Trade Organization: A Cluster Analysis of Country Groups. IFPRI Discussion Paper 59. Washington, DC: International Food Policy Research Institute.

Dorosh, P., S. Robinson, and H. Ahmed. 2009. Economic Implications of Foreign Exchange Rationing in Ethiopia. ESSP2 Discussion Paper 009. Addis Ababa, Ethiopia: International Food Policy Research Institute.

Eastwood, R., and M. Lipton. 2000. "Pro-Poor Growth and Pro-Growth Poverty Reduction: Meaning, Evidence, and Policy Implications." Asian Development Review 18 (2): 22-58.

Fan, S., ed. 2008. Public Expenditures, Growth, and Poverty: Lessons from Developing Countries. Baltimore: Johns Hopkins University Press. 
FAO (Food and Agriculture Organization of the United Nations). 2014. FAOSTAT database. Accessed January 22, 2015. http://faostat3.fao.org/home/E.

G20 (The Group of Twenty). 2011. Price Volatility in Food and Agricultural Markets: Policy Responses. Policy Report including contributions by FAO, IFAD, IMF, OECD, UNCTAD, WFP, the World Bank, the WTO, IFPRI and the UN HLTF. 2 June 2011. Rome: Food and Agriculture Organization of the United Nations.

Gilbert, C. L., and C. W. Morgan. 2010. Has Food Price Volatility Risen? University of Trento, Department of Economics Working Paper 2/2010. Trento, Italy: University of Trento.

Haggblade, S., and P. Hazell. 2010. Successes in African Agriculture: Lessons for the Future. IFPRI Issue Brief 63. Washington, DC: International Food Policy Research Institute.

Haggblade, S., P. Hazell, and T. Reardon, ed. 2007. Transforming the Rural Non-Farm Economy. Baltimore: Johns Hopkins University Press.

Hazell, P., G. Shields, and D. Shields. 2005. "The Nature and Extent of Domestic Sources of Food Price Instability and Risk." Paper presented at the international workshop Managing Food Price Instability in Low-Income Countries, Washington, DC, February 28-March 1.

Headey, D. 2014. Food Prices and Poverty Reduction in the Long Run. IFPRI Discussion Paper 01331. Washington, DC: International Food Policy Research Institute.

IMF (International Monetary Fund). Various years. International Financial Statistics database. http://data.imf.org/?sk=5DABAFF2-C5AD-4D27-A175-1253419C02D1.

Ivanic, M., and W. Martin. 2014. Short- and Long-Run Impacts of Food Price Changes on Poverty. Policy Research Working Paper 7011. Washington, DC: World Bank.

Mogues, T., B. Yu, S. Fan, and L. McBride. 2012. The Impacts of Public Investment in and for Agriculture: Synthesis of the Existing Evidence. IFPRI Discussion Paper 01217. Washington, DC: International Food Policy Research Institute.

Mundell, R. 2002. "Commodity Prices, Exchange Rates and the International Monetary System." Presentation at the Consultation on Agricultural Commodity Price Problems, Commodities and Trade Division, Food and Agriculture Organization of the United Nations, Rome, March 25-26. www.fao.org/docrep/006/Y4344E/y4344e04.htm.

Rashid, S., and S. Lemma. 2011. Strategic Grain Reserves in Ethiopia: Institutional Design and Operational Performance. IFPRI Discussion Paper 01054. Washington, DC: International Food Policy Research Institute.

Ravn, M. O., and H. Uhlig. 2002. "On Adjusting the Hodrick-Prescott Filter for the Frequency of Observations." Review of Economics and Statistics 84: 371-375.

Rotemberg, J. J., and M. Woodford. 1999. "The Cyclical Behavior of Prices and Costs.” In Handbook of Macroeconomics. Vol. 1, 1051-1135. Amsterdam: North Holland.

Stock, J. S., and M. Watson. 1988. "Variable Trends in Economic Time Series." Journal of Economic Perspectives 2 (3): $147-174$.

Tadesse, G., B. Algieri, M. Kalkuhl, and J. von Braun. 2014. "Drivers and Triggers of International Food Price Spikes and Volatility." Food Policy 47: 117-128.

Timmer, P. 1989. "Food Price Policy: The Rationale for Government Intervention.” Food Policy 14 (1): 17-27.

Timmer, C. P., W. P. Falcon, and S. R. Pearson. 1983. Food Policy Analysis. Baltimore: Johns Hopkins University Press.

Torero, M. 2012. “Food Prices: Riding the Rollercoaster.” In 2011 Global Food Policy Report. Washington, DC: International Food Policy Research Institute.

Triantafyllou, A., G. Dotsis, and A. Sarris. 2013. Volatility Forecasting in Agricultural Commodity Markets. Athens, Greece: University of Athens.http://www.aueb.gr/conferences/Crete2014/papers/Triantafyllou.pdf.

World Bank. 2005. Managing Food Price Risks and Instability in an Environment of Market Liberalization. Agriculture and Rural Development Department Report 32727-GLB. Washington, DC: World Bank. 


\section{RECENT IFPRI DISCUSSION PAPERS}

\section{For earlier discussion papers, please go to www.ifpri.org/pubs/pubs.htm\#dp. All discussion papers can be downloaded free of charge.}

1504. Changes in Ghanaian farming systems: Stagnation or a quiet transformation? Nazaire Houssou, Michael Johnson, Shashidhara Kolavalli, and Collins Asante-Addo, 2016.

1503. Returns to agricultural public spending in Ghana: Cocoa versus Noncocoa subsector. Samuel Benin, 2016.

1501. Challenges in implementing a small-scale farmers' capacity-building program: The case of the food production, processing, and marketing project in the Democratic Republic of Congo. Catherine Ragasa, Ephraim Nkonya, John Ulimwengu, and Josée Randriamamonjy, 2016.

1500. Leveling the field for biofuels: Comparing the economic and environmental impacts of biofuel and other export crops in Malawi. Franziska Schuenemann, James Thurlow, and Manfred Zeller, 2016.

1499. Farm transition and indigenous growth: The rise to medium- and large-scale farming in Ghana. Nazaire Houssou, Antony Chapoto, and Collins Asante-Addo, 2016.

1498. The impact of agricultural extension services in the context of a heavily subsidized input system: The case of Malawi. Catherine Ragasa, John Mazunda, and Mariam Kadzamira, 2016.

1497. Ghana's macroeconomic crisis: Causes, consequences, and policy responses. Stephen D. Younger, 2016.

1496. Temporary and permanent migrant selection: Theory and evidence of ability-search cost dynamics. Joyce J. Chen, Katrina Kosec, and Valerie Mueller, 2015.

1495. The effect of insurance enrollment on maternal and child healthcare use: The case of Ghana. Gissele Gajate-Garrido and Clement Ahiadeke, 2015.

1494. Stories of change in nutrition: A tool pool. Stuart Gillespie and Mara van den Bold, 2015.

1493. Optimal tariffs with smuggling: A spatial analysis of Nigerian rice policy options. Michael Johnson and Paul Dorosh, 2015.

1492. Smallholders and land tenure in Ghana: Aligning context, empirics, and policy. Isabel Lambrecht and Sarah Asare, 2015.

1491. Returns to agricultural public spending in Africa South of the Sahara. Samuel Benin, 2015.

1490. Lost in translation: The Fractured conversation about trade and food security. Eugenio Díaz-Bonilla, 2015.

1489. Gender roles and food safety in 20 informal livestock and fish value chains. Delia Grace, Kristina Roesel, Erastus Kang'ethe, Bassirou Bonfoh, and Sophie Theis, 2015.

1488. Farm household typologies and mechanization patterns in Nepal Terai: Descriptive analysis of the Nepal Living Standards Survey. Hiroyuki Takeshima, Rajendra Prasad Adhikari, Mahendra Nath Poudel, and Anjani Kumar, 2015.

1487. Public-private partnerships and the reduction of undernutrition in developing countries. John Hoddinott, Stuart Gillespie, and Sivan Yosef, 2015.

1486. How does women's time in reproductive work and agriculture affect maternal and child nutrition?: Evidence from Bangladesh, Cambodia, Ghana, Mozambique, and Nepal. Hitomi Komatsu, Hazel Jean L. Malapit, and Sophie Theis, 2015.

1485. US maize data reveals adaptation to heat and water stress. Timothy S. Thomas, 2015.

1484. Customary tenure and innovative measures of safeguarding land rights in Africa: The community land initiative (iniciativa de terras comunitárias) in Mozambique. Hosaena Ghebru, Raul Pitoro, and Sileshi Woldeyohannes, 2015.

1483. The International Model for Policy Analysis of Agricultural Commodities and Trade (IMPACT): Model description for version 3. Sherman Robinson, Daniel Mason-D’Croz, Shahnila Islam, Timothy B. Sulser, Richard Robertson, Tingju Zhu, Arthur Gueneau, Gauthier Pitois, and Mark Rosegrant, 2015.

1482. Enhancing food security in South Sudan: The role of public food stocks and cereal imports. Paul A. Dorosh, Shahidur Rashid, Abigail Childs, and Joanna van Asselt, 2015. 
INTERNATIONAL FOOD POLICY

RESEARCH INSTITUTE

www.ifpri.org

IFPRI HEADQUARTERS

$2033 \mathrm{~K}$ Street, NW

Washington, DC 20006-1002 USA

Tel.: +1-202-862-5600

Fax: +1-202-467-4439

Email: ifpri@cgiar.org 